\title{
Decreased expression of FOXF2 as new predictor of poor prognosis in stage I non-small cell lung cancer
}

\author{
Peng-Zhou Kong ${ }^{1,2, *}$, Guang-Ming Li ${ }^{3, *}$, Yin Tian ${ }^{4,5}$, Bin Song ${ }^{1,6}$, RuYi Shi ${ }^{1,7}$ \\ ${ }^{1}$ Translational Medicine Research Center, Shanxi Medical University, Taiyuan 030001, China \\ ${ }^{2}$ Key Laboratory of Cellular Physiology, Ministry of Education, Shanxi Medical University, Taiyuan 030001, China \\ ${ }^{3}$ School of Basic Medical Sciences, Tianjin Medical University, Tianjin 300070, China \\ ${ }^{4}$ Department of General Surgery, The Second Hospital of JingZhou, JingZhou 434000, China \\ ${ }^{5}$ Department of Biochemistry and Molecular Biology, Tianjin Medical University Cancer Institute and Hospital, Tianjin 300060, \\ China \\ ${ }^{6}$ Department of Oncology, The First Hospital, Shanxi Medical University, Taiyuan 030001, China \\ ${ }^{7}$ Department of Cell Biology and Genetics, Shanxi Medical University, Taiyuan 030001, China \\ *Both authors have shared co-first authorship \\ Correspondence to: Peng-Zhou Kong, email: kongpzh@163.com \\ Keywords: FOXF2, non-small-cell lung carcinoma, survival, clinical stage \\ Received: April 13,2016 Accepted: July 10,2016 Published: July 28, 2016
}

\section{ABSTRACT}

Background: Forkhead box F2 (FOXF2) is relatively limited to the adult lung, but its contribution to non-small cell lung cancer (NSCLC) prognosis is unclear.

Results: FOXF2 mRNA levels in NSCLC were lower than that in paired normal lung tissues $(P=0.012)$. The FOXF2 $2_{\text {low }}$ patients had shorter survival time than the FOXF2 $2_{\text {high }}$ patients $(P=0.024)$ especially in stage $I(P=0.002)$, chemotherapy $(P=0.018)$ and $<60$ age groups $(P=0.002)$. Lower FOXF2 mRNA levels could independently predict poorer survival for patients with NSCLC $(H R=2.384,95 \%$ CI $=1.241-4.577 ; P=$ $0.009)$, especially in stage I $(H R=4.367,95 \% C I=1.599-11.925 ; P=0.004)$. The two independent datasets confirmed our findings.

Methods: We examined FOXF2 mRNA levels in 84 primary NSCLC and 8 normal lung tissues using qRT-PCR. Rank-sum tests and chi-square tests were used to assess the differences among groups with various clinicopathological factors. Kaplan-Meier tests were used to compare survival status in patients with different FOXF2 mRNA levels. Cox proportional hazards regression model was used to evaluate the predictive value of FOXF2 mRNA level in NSCLC patients. Independent validation was performed using an independent dataset (98 samples) and an online survival analysis software Kaplan-Meier plotter (1928 samples).

Conclusions: Our results demonstrated that decreased FOXF2 expression is an independent predictive factor for poor prognosis of patients with NSCLC, especially in stage I NSCLC.

\section{INTRODUCTION}

Lung cancer is by far the main cause of cancerrelated death. It is the most frequently diagnosed cancer and the leading cause of cancer death in males and the second in females $[1,2]$. Lung cancer is usually classified into two main types: small cell lung cancer (SCLC) and non-small cell lung cancer (NSCLC) depending upon the microscopic appearance of the tumor cells. NSCLC is the most common type of lung cancer, accounting for $85 \%$ of all lung cancers diagnosed [3]. Currently, for NSCLC patients, the most accurate prognostic factors are tumor size, node, and tumor-node-metastasis (TNM) staging. However, as a heterogeneous disease, even with similar clinical and pathological features, and similar TNM stage, patients with NSCLC may have different outcomes 
due to distinct inherent biological characteristics of the tumor. Therefore, new prognostic factors are needed to be determined to better predict the outcome of lung cancer and provide a potential improvement in better treatment, especially within a given TNM stage.

Forkhead box F2 (FOXF2) is a member of Forkhead box transcription factors family, which is characterized by a highly conserved 110 amino acid DNA binding domain [4] and function as an activator or inhibitor of gene transcription [5]. Human FOXF2 was initially identified in 1994 [6], and the gene is located at $6 \mathrm{p} 25.3$ [7]. FOXF2 was found to have a relatively restricted highexpression limited to the adult lung and transactivated pulmonary surfactant proteins $\mathrm{A}, \mathrm{B}$, and $\mathrm{C}$ (SPA, SPB, and SPC) [8]; however, later studies revealed it had a more widespread expression [9]. FOXF2 plays an important role in embryonic development [10, 11], extracellular matrix synthesis [11] and epithelial-mesenchymal interaction [9], and the knockout of foxf2 mice present with cleft palate or a range of defects, including megacolon, colorectal muscle hypoplasia and agangliosis.

In cancer, FOXF2 has been considered as a potential tumor suppressor. In our previous studies, decreased FOXF2 expression was associated with early-onset metastasis and poor prognosis for patients with triplenegative breast cancer [12], and further studies showed that FOXF2 can inhibit epithelial-mesenchymal transition (EMT) and metastasis of basal-like breast cancer by targeting TWIST1 [13] and FOXC2 [14] directly. In prostate cancer, FOXF2 mRNA was decreased $[15,16]$ compared to normal prostate tissues, and it is a potential target genes of miR-182-5p, which promotes cell invasion and proliferation by down- regulating FOXF2, RECK and MTSS1 genes [17]. And in breast cancer FOXF2 is a target gene of miR-301, which acts as a crucial oncogene to promote metastatic tumor progression [18]. The evidence given above indicates FOXF2 may act as a tumor suppressor in tumorigenesis and metastasis.

However, the role of FOXF2 in lung cancer is unknown, especially in NSCLC. In this current study, our results showed that mRNA of FOXF2 was significantly decreased in NSCLC tissues compared to paired normal lung tissues. Additionally decreased FOXF2 mRNA expression was associated with poor prognosis in Stage I NSCLC patients, and it could predict poor prognosis for patients with Stage I NSCLC independently.

\section{RESULTS}

\section{Expression level of FOXF2 mRNA in lung cancer tissues}

First, we measured the FOXF2 mRNA levels in primary lung cancer and paired normal samples from patients with NSCLC using real-time PCR analysis. The mRNA level of FOXF2 ranged from 1.79E-04 to 157.47 in primary lung cancers and the median was $5.86 \mathrm{E}$ 03 . The mRNA level of FOXF2 ranged from 3.20E-02 to $2.11 \mathrm{E}-01$ in normal lung tissues and the median was 6.86E-02. Significant difference in FOXF2 mRNA levels was found between paired primary lung cancers and normal lung tissues $(P=0.012, \mathrm{Z}=-2.521$, Figure 1). All cancer samples were grouped into two groups: $F O X F 2_{\text {low }}$ $(\leq 3.75 \mathrm{E}-03)$ and $F O X F 2_{\text {high }}(>3.75 \mathrm{E}-03)$, according to the ROC curve analyses (AUC $=0.657, P=0.021,95 \%$ confidence interval:0.531-0.782). The disease-free survival (DFS) of $F O X F 2_{\text {low }}$ ranged from 1 month to 54 months, and the median was 26 months. The DFS of $F O X F 2_{\text {high }}$ ranged from 1 month to 59 months, and the median was 46 months. Rank-sum test shown the patients in the $F O X F 2_{\text {high }}$ group had a longer survival time than those in the $F O X F 2_{\text {low }}$ group $(\mathrm{Z}=-2.347, P=0.019)$.

\section{Correlation between the mRNA level of FOXF2 and clinicopathologic factors}

To establish the link between FOXF2 mRNA levels in primary tumors and clinicopathological features of lung cancer, we analyzed the FOXF2 mRNA levels among different clinicopathologic groups. No significant difference of $F O X F 2$ mRNA levels was found in patients with different gender, age, histology, clinical stage, family history, and smoking history $(P>0.05$, Table 1$)$. Although no significant difference was found among the three tumor size groups $(P=0.063$, Table 1$)$, the mRNA of FOXF2 in the size $\leq 3 \mathrm{~cm}$ group was significantly higher than in the size $>7 \mathrm{~cm}$ group $(P=0.037$, Table 1$)$.

\section{FOXF2 mRNA levels reflected the DFS status in NSCLC patients}

To explore the relationship between FOXF2 mRNA levels in primary tumors and DFS status of lung cancer patients, Kaplan-Meier survival analysis was used to compare the DFS status of lung cancer patients with different $F O X F 2$ mRNA expression status. In the overall study population $(n=84)$, patients with low FOXF2 levels had a statistically lower cumulative DFS than those with high FOXF2 levels ( $P=0.024$, Figure 2A). In different gender, age $\geq 60$, tumor size, histology types, family, or smoking history groups, there was no difference in disease-free survival time between $F O X F 2_{\text {low }}$ and $F O X F 2_{\text {high }}$ patients. In the age $<60$ group, the patients with low $F O X F 2$ levels had a statistically lower cumulative DFS than those with high $F O X F 2$ levels $(P=0.002$, Figure $2 \mathrm{~B})$. When receiving chemotherapy, the patients with low $F O X F 2$ levels had a statistically shorter cumulative DFS than those with high $F O X F 2$ levels $(P=0.018$, Figure $2 \mathrm{C}$ ). Although there was no difference in stage II and III groups, in the stage I group $F O X F 2$ expression significantly affected the survival time of lung cancer patients and the $F O X F 2_{\text {low }}$ group had a significantly lower 
survival time than the $F O X F 2_{\text {high }}$ group $(P=0.002$, Figure 2D). And the 7 patients in stage IV all belong to FOXF2 $2_{\text {low }}$ group and didn't perform Kaplan-Meier analysis and Logrank test.

\section{Prediction of disease-free survival based on the mRNA level of FOXF2}

To evaluate the predictive value of $F O X F 2$ mRNA level for DFS status in lung cancer patients, FOXF2 mRNA and other factors were used to make the univariate analysis by cox proportional hazard regression model. Univariate analysis showed that $F O X F 2_{\text {low }}$ and tumor size were significant risk factors in predicting DFS status in the overall study population $(F O X F 2$, hazard ratio $(\mathrm{HR})=$ $1.927,95 \% \mathrm{CI}=1.077-3.449, P=0.027 ; \leq 3$ vs. $>7, \mathrm{HR}$ $=0.308,95 \% \mathrm{CI}=0.111-0.854, P=0.024 ; 3-7$ vs. $>7$, $\mathrm{HR}=0.256,95 \% \mathrm{CI}=0.097-0.672, P=0.006)$ and in stage I NSCLC patients $(F O X F 2, \mathrm{HR}=3.526,95 \% \mathrm{CI}=$ $1.510-8.231 ; P=0.004 ; \leq 3$ vs. $>7, \mathrm{HR}=0.345,95 \% \mathrm{CI}=$ $0.110-1.080, P=0.067 ; 3-7$ vs. $>7, \mathrm{HR}=0.222,95 \% \mathrm{CI}$ $=0.075-0.662, P=0.007)$ (Table 2).

Furthermore, multivariate analysis was carried out to evaluate the FOXF2 mRNA and other significant factors with a cox proportional hazard regression model. The result showed that in patients with NSCLC, FOXF2 mRNA level was an independent prediction factor for survival and the $F O X F 2_{\text {low }}$ patients had a shorter survival time than the $F O X F 2_{\text {high }}$ patients $(\mathrm{HR}=2.384,95 \% \mathrm{CI}$ $=1.241-4.577 ; P=0.009$ ) especially in stage I NSCLC patients $(\mathrm{HR}=4.367,95 \% \mathrm{CI}=1.599-11.925 ; P=0.004)$ (Table 3, Figure 3).

\section{Independent validation}

The prognostic value of expression of FOXF2 mRNA was validated in an independent dataset consisting of 17 normal lung tissues and 98 lung cancer tissues from the study of Bhattacharjee [19]. In these validation samples, the median mRNA level of FOXF2 in primary lung cancers was lower than that in normal lung tissues (median level, -1.450945 vs 0.16391; $P=2.40 \mathrm{E}-5$ ). NSCLC patients with $F O X F 2_{\text {low }}$ had a poorer DFS (median months, 37.6 vs $47.2 ; P=0.065$ ) than $F O X F 2_{\text {high }}$ patients. Kaplan-Meier survival analysis showed that $F O X F 2_{\text {low }}$ patients had a poorer DFS than $F O X F 2_{\text {high }}$ patients in the overall study population $(P=0.044$; Figure $4 \mathrm{~A})$ and in the stage I group $(P=0.011$, Figure 4B). The multivariate analysis showed that FOXF2 mRNA level was an independent prediction factor for overall survival $(\mathrm{HR}=1.880,95 \% \mathrm{CI}: 1.082-3.268, P=0.025)$ and in stage I group $(\mathrm{HR}=2.278,95 \% \mathrm{CI}: 1.106-4.690, P=$ 0.025) (see Supplementary Table S1 and S2).

Another validation was performed using an online survival analysis software, Kaplan-Meier plotter, consisting of 2,437 lung cancer patients with a mean follow-up of 49 months [20]. In the validation samples $(\mathrm{n}=1928)$, Kaplan-Meier survival analysis showed that NSCLC patients with $F O X F 2_{\text {low }}$ had a poorer 5-year DFS than $F O X F 2_{\text {high }}$ patients in the overall population $(\mathrm{HR}=$ $0.6(0.53-0.7), \log$-rank $P=1.8 \mathrm{e}-12$, Figure $\mathrm{S} 1 \mathrm{~A})$ and in the stage I group $(\mathrm{HR}=0.47(0.35-0.65), \log$-rank $P$ $=1.2 \mathrm{e}-06$, Figure S1B). There was no difference between $F O X F 2_{\text {low }}$ and $F O X F 2_{\text {high }}$ patients in the stage II group (HR $=1.09(0.74-1.61), \log$-rank $P=0.66$, Figure $\mathrm{S} 1 \mathrm{C})$ or in

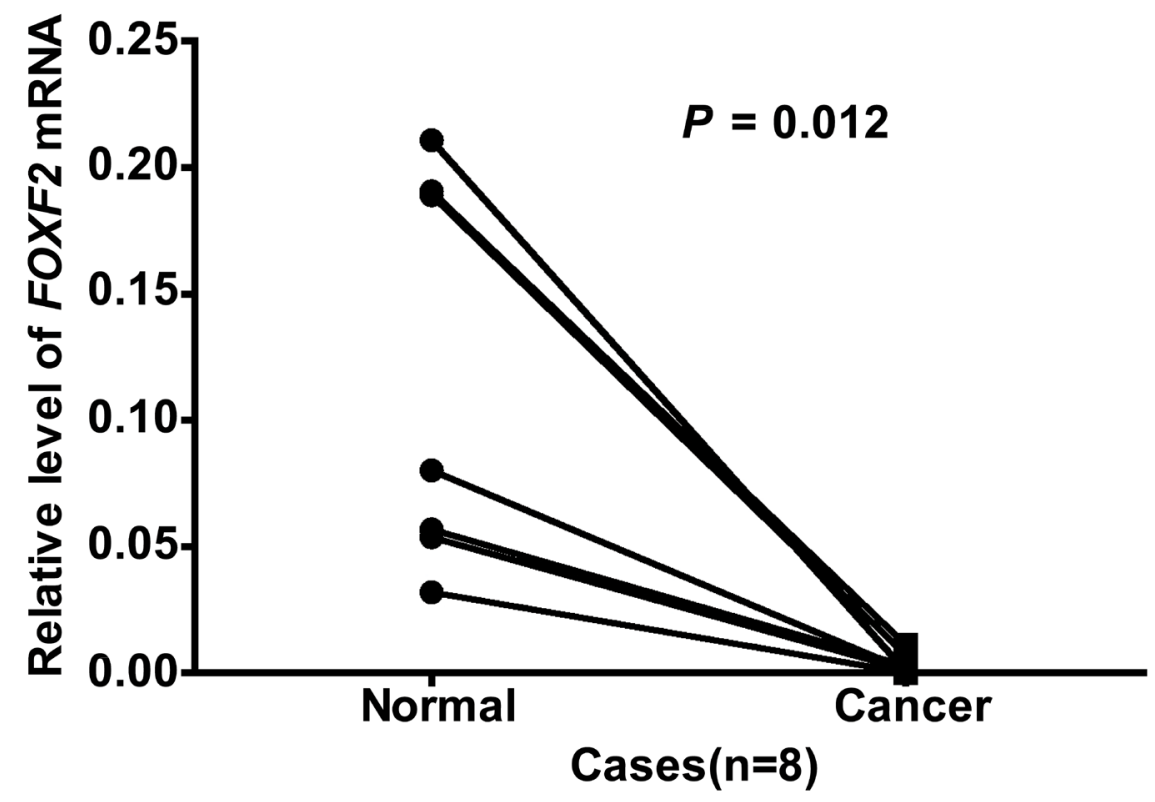

Figure 1: Comparison of FOXF2 mRNA expression in paired lung tumor tissues and normal tissues. The mRNA of FOXF2 was significantly decreased in cancer tissue compared with paired normal lung tissue in all 8 cases. 
Table 1: Association of $F O X F 2$ mRNA levels with clinicopathological factors in patients with NSCLC

\begin{tabular}{|c|c|c|c|c|c|c|c|c|}
\hline \multirow[t]{2}{*}{ Variables } & \multirow[t]{2}{*}{ Cases } & \multirow{2}{*}{$\begin{array}{l}\text { Median levels of } \\
F O X F 2\left(1 \times 10^{-3}\right)\end{array}$} & \multicolumn{2}{|c|}{ Rank sum tests } & \multicolumn{2}{|c|}{$F O X F 2$ mRNA level } & \multicolumn{2}{|c|}{ Chi-square test } \\
\hline & & & $\mathrm{Z} / \chi^{2}$ & $P$ & Low (\%) & High (\%) & $\chi^{2}$ & $P$ \\
\hline \multicolumn{9}{|l|}{ Age (years) } \\
\hline$<60$ & 34 & $7.16(0.18-157477)$ & -1.394 & 0.163 & $10(29.4 \%)$ & $24(70.6 \%)$ & 1.377 & 0.241 \\
\hline$\geq 60$ & 50 & $4.69(0.27-622.01)$ & & & $21(42.0 \%)$ & $29(58.0 \%)$ & & \\
\hline \multicolumn{9}{|l|}{ Gender } \\
\hline Female & 22 & $9.09(0.27-217.19)$ & -1.312 & 0.189 & $6(27.3 \%)$ & $16(72.7 \%)$ & 1.188 & 0.276 \\
\hline Male & 62 & $4.87(0.18-157477)$ & & & $25(40.3 \%)$ & $37(59.7 \%)$ & & \\
\hline \multicolumn{9}{|l|}{ Family history } \\
\hline Yes & 9 & $7.15(1.72-29.18)$ & -0.108 & 0.914 & $4(44.4 \%)$ & $5(55.6 \%)$ & 0.246 & 0.620 \\
\hline No & 75 & $5.22(0.18-157477)$ & & & $27(36.0 \%)$ & $48(64.0 \%)$ & & \\
\hline \multicolumn{9}{|l|}{ Smoking history } \\
\hline Current & 68 & $4.96(0.18-157477)$ & -1.367 & 0.172 & $25(36.8 \%)$ & $43(63.2 \%)$ & 0.003 & 0.956 \\
\hline Never & 16 & $10.61(0.51-217.19)$ & & & $6(37.5 \%)$ & $10(62.5 \%)$ & & \\
\hline \multicolumn{9}{|l|}{ Tumor size (cm) } \\
\hline$\leq 3$ & 27 & $7.15(0.51-49.65)$ & 1.648 & 0.439 & $7(25.9 \%)$ & $20(74.1 \%)$ & 5.440 & 0.063 \\
\hline $3-7$ & 52 & $5.86(0.18-157477)$ & & & $20(38.5 \%)$ & $32(61.5 \%)$ & & $0.265^{*}$ \\
\hline \multirow[t]{2}{*}{$>7$} & 5 & $2.40(1.18-261.88)$ & & & $4(80.0 \%)$ & $1(20.0 \%)$ & & $0.037 * *$ \\
\hline & & & & & & & & $0.151 * * *$ \\
\hline \multicolumn{9}{|l|}{ Clinical stage } \\
\hline I & 42 & $4.96(0.64-65.56)$ & 1.118 & 0.572 & $18(42.9 \%)$ & $24(57.1 \%)$ & 1.859 & 0.395 \\
\hline II & 22 & $7.08(0.27-261.88)$ & & & $8(36.4 \%)$ & $14(63.6 \%)$ & & \\
\hline III-IV & 20 & $6.00(0.18-157477)$ & & & $5(25.0 \%)$ & $15(75.0 \%)$ & & \\
\hline \multicolumn{9}{|l|}{ Histology type } \\
\hline $\begin{array}{l}\text { Squamous cell } \\
\text { carcinoma }\end{array}$ & 62 & $4.87(0.18-157477)$ & -1.628 & 0.104 & $25(40.3 \%)$ & $37(59.7 \%)$ & 1.188 & 0.276 \\
\hline Adenocarcinoma & 22 & $7.74(0.27-217.19)$ & & & $6(27.3 \%)$ & $16(72.7 \%)$ & & \\
\hline
\end{tabular}

$* \leq 3$ vs $3-7 ; * * \leq 3$ vs $>7 ; * * * 3-7$ vs $>7$.

the stage III group $(\mathrm{HR}=0.67(0.38-1.21)$, log-rank $P$ $=0.19$, Figure S1D). Patients with $F O X F 2_{\text {low }}$ had a poorer DFS than $F O X F 2_{\text {high }}$ patients in the lung adenocarcinoma population $(\mathrm{HR}=0.4(0.29-0.54)$, log-rank $P=1.6 \mathrm{e}-$ 09 , Figure S2A), in the lung squamous cell carcinoma population $(\mathrm{HR}=0.66(0.49-0.89), \log$-rank $P=0.0057$, Figure S2B), and in the never smoked group ( $\mathrm{HR}=0.39$ $(0.2-0.74), \log$-rank $P=0.0027$, Figure S2C) and in the smoked group respectively $(\mathrm{HR}=0.54(0.41-0.69)$, logrank $P=1.8 \mathrm{e}-06$, Figure S2D).

\section{DISCUSSION}

Forkhead proteins are a large family of transcription factors and are commonly associated with development. Recent studies have shown that the FOX transcription factors play important roles in tumor progression in several types of cancers [21-32]. In our present study, the mRNA level of FOXF2 was found to be decreased in primary lung cancer compared with paired normal lung tissue, and it negatively correlated with the size of lung cancer. 
Furthermore, low expression of $F O X F 2$ was associated with the worst outcome of NSCLC patients with clinical stage I. And two independent validation studies ( $\mathrm{n}=98$ and $n=1928$ respectively) confirmed our findings. So we suppose FOXF2 is a predictor of NSCLC prognosis.

It has been reported that FOXF2 plays an important role in epithelial-mesenchymal interactions [9] and inhibition of Foxf2 leads to loss of collagen synthesis [11]. This indicates FOXF2 is an important regulator in extracellular matrix (ECM) production and remodeling [11]. FOXF2 modulates ECM balance and remodeling through regulating the balance between MMPs and
TIMPs $[15,16]$. In prostate cancer, MMP1 was downregulated by FOXF2 whereas TIMP3, one of MMPs inhibitors, was up-regulated by FOXF2. Additionally, in prostate cancer, FOXF2 has an opposite regulatory effect with TGF $\beta 3$ pathways $[15,16]$, which is described as triggering EMT via MMP-dependent mechanisms $[33,34]$. In our previous study, we found that FOXF2 is a novel EMT-suppressor [13] and decreased FOXF2 is associated with poor prognosis of patients with basallike breast cancer [12]. Our current results show FOXF2 levels were decreased in lung cancer tissue and its downregulation is associated with the increased tumor size. It is

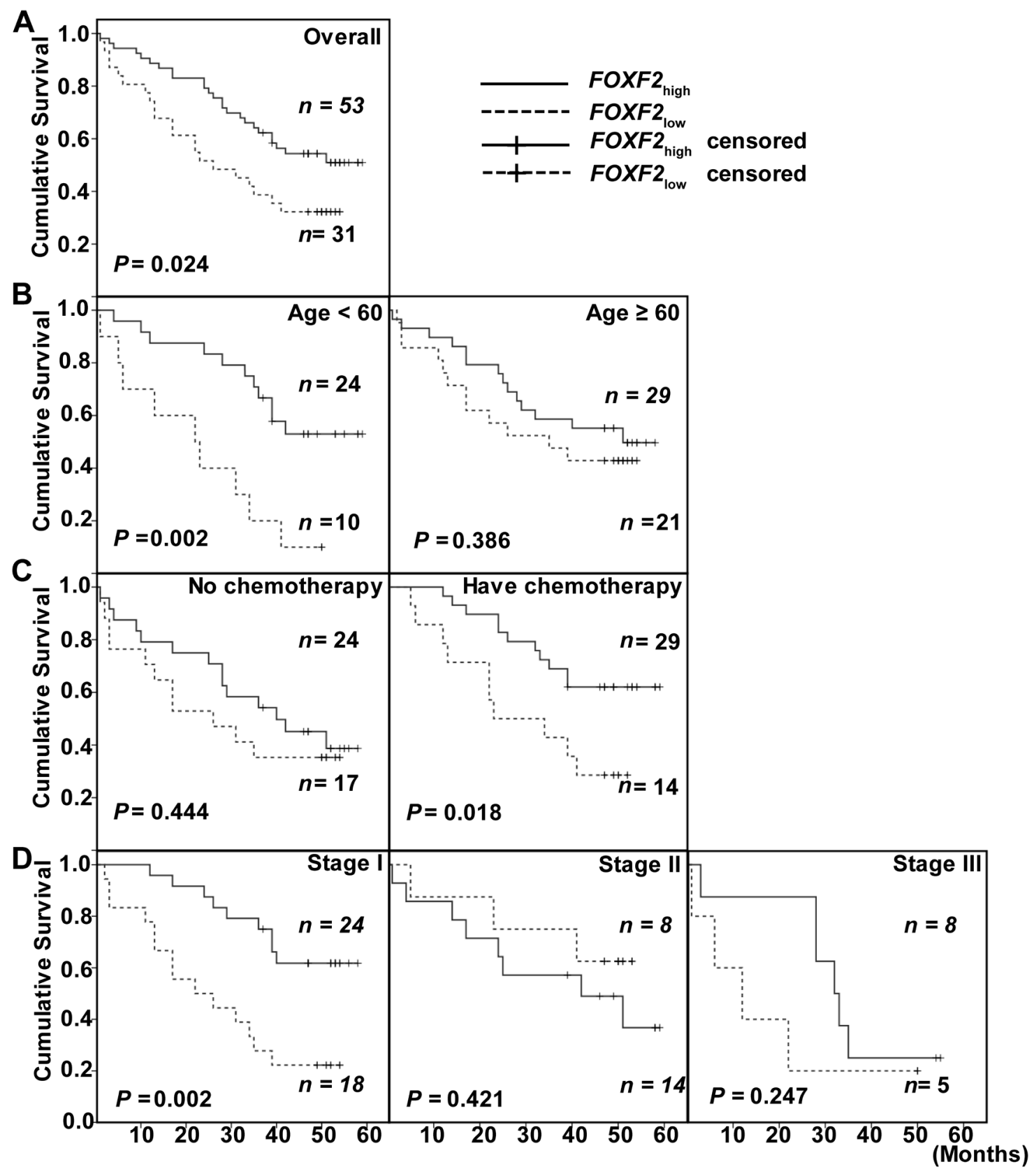

Figure 2: Kaplan-Meier survival curves of patients with different $F O X F 2 \boldsymbol{m} \boldsymbol{R} \boldsymbol{A} \boldsymbol{A}$ expression. A. Cumulative DFS in the overall study population. B. Cumulative DFS of patients in the age $<60$ group and in the age $\geq 60$ group. C. Cumulative DFS in patients accepting chemotherapy or no chemotherapy. D. Cumulative DFS in stage I, II, III NSCLC. 
Table 2: Univariate and multivariate Cox models for the association between survival and clinicopathological factors in patients with NSCLC

\begin{tabular}{|c|c|c|c|c|c|c|c|}
\hline \multirow{2}{*}{ Variables } & & \multicolumn{2}{|c|}{ Univariate analysis } & \multicolumn{4}{|c|}{ Multivariate analysis } \\
\hline & & HR & $95 \%$ CI & $P$-value & HR & $95 \% \mathrm{CI}$ & $P$-value \\
\hline Age & $<60$ vs. $\geq 60$ & 1.127 & $0.629-2.021$ & 0.688 & 1.194 & $0.612-2.331$ & 0.603 \\
\hline Gender & Female vs Male & 0.472 & $0.220-1.013$ & 0.054 & 0.520 & $0.214-1.263$ & 0.149 \\
\hline Histology & Sq. vs. Ade. & 1.094 & $0.566-2.113$ & 0.789 & 0.840 & $0.382-1.850$ & 0.666 \\
\hline Smoking history & no vs yes & 0.679 & $0.303-1.518$ & 0.345 & 0.563 & $0.197-1.612$ & 0.285 \\
\hline Family history & no vs yes & 0.761 & $0.300-1.927$ & 0.564 & 0.864 & $0.323-2.314$ & 0.772 \\
\hline Tumor size (cm) & $\begin{array}{l}\leq 3 \text { vs. }>7 \\
3-7 \text { vs. }>7\end{array}$ & $\begin{array}{l}0.308 \\
0.256\end{array}$ & $\begin{array}{l}0.111-0.854 \\
0.097-0.672\end{array}$ & $\begin{array}{l}0.024 \\
0.006\end{array}$ & $\begin{array}{l}0.345 \\
0.222\end{array}$ & $\begin{array}{l}0.110-1.080 \\
0.075-0.662\end{array}$ & $\begin{array}{l}0.067 \\
0.007\end{array}$ \\
\hline Clinical stage & $\begin{array}{c}\text { II vs. I } \\
\text { III-IV vs. I }\end{array}$ & $\begin{array}{l}0.898 \\
1.277\end{array}$ & $\begin{array}{c}0.437-1.843 \\
0.635-2.571\end{array}$ & $\begin{array}{l}0.769 \\
0.492\end{array}$ & $\begin{array}{l}0.674 \\
1.862\end{array}$ & $\begin{array}{l}0.310-1.465 \\
0.859-4.035\end{array}$ & $\begin{array}{l}0.320 \\
0.115\end{array}$ \\
\hline$F O X F 2$ mRNA & Low vs. High & 1.927 & $1.077-3.449$ & 0.027 & 2.384 & $1.241-4.577$ & 0.009 \\
\hline
\end{tabular}

Sq. means Squamous cell carcinoma.

Ade. means Adenocarcinoma

Table 3: Univariate and multivariate Cox models for the association between survival and clinicopathological factors in patients with stage I NSCLC

\begin{tabular}{|c|c|c|c|c|c|c|c|}
\hline \multirow{2}{*}{ Variables } & & \multicolumn{2}{|c|}{ Univariate analysis } & \multicolumn{4}{|c|}{ Multivariate analysis } \\
\hline & & HR & $95 \% \mathrm{CI}$ & $P$-value & HR & $95 \% \mathrm{CI}$ & $P$-value \\
\hline Age & $<60$ vs. $\geq 60$ & 1.350 & $0.570-3.196$ & 0.494 & 1.407 & $0.526-3.758$ & 0.496 \\
\hline Gender & Female vs Male & 0.535 & $0.182-1.575$ & 0.256 & 0.458 & $0.109-1.917$ & 0.285 \\
\hline Histology & Sq. vs. ade. & 0.710 & $0.300-1.678$ & 0.435 & 0.619 & $0.186-2.058$ & 0.434 \\
\hline Smoking history & no vs. yes & 1.375 & $0.542-3.493$ & 0.503 & 1.594 & $0.399-6.370$ & 0.510 \\
\hline Family history & no vs. yes & 0.869 & $0.117-6.464$ & 0.891 & 0.503 & $0.054-4.653$ & 0.545 \\
\hline Tumor size (cm) & $\leq 3$ vs. $3-7$ & 1.621 & $0.601-4.371$ & 0.340 & 1.149 & $0.315-4.188$ & 0.834 \\
\hline$F O X F 2$ mRNA & Low vs. High & 3.526 & $1.510-8.231$ & 0.004 & 4.367 & $1.599-11.925$ & 0.004 \\
\hline
\end{tabular}

Sq. means Squamous cell carcinoma.

Ade. means Adenocarcinoma

possible that the decreased FOXF2 leads to an imbalance in matrix synthesis/degradation and provides a suitable environment for the growth and metastasis of cancer cells and leads to a worse outcome at last. So FOXF2 might be a tumor suppressor and work by maintaining the balance of ECM and inhibition of EMT. However, recent studies showed Foxf2 induced robust EMT, migration, invasion and metastasis in lung cancer cells [35], and inhibition of miR301 enhances Akt-mediated cell proliferation and FoxF2 is a regulatory target for miR301 [36]. Thus, further investigations are required to identify the role of FOXF2 in lung cancer and other cancer types.

The most common cause of lung cancer is long-term exposure to tobacco smoke $[37,38]$. Tharappel et al. have shown that cigarette smoke exposure leads to quantitative increases in DNA binding activities of Foxf2 after only 10 days in mice [39]. In the present study, although there is no statistical significance, the expression of FOXF2 mRNA in the non-smoking group is higher than in the smoking group. However, the effect of smoke on FOXF2 in lung cancer needs to be investigated furtherly.

Another interesting thing is that in age $<60$ group decreased $F O X F 2$ mRNA levels may be a marker of lower survival of NSCLC. It has been reported that age is an important predictor of prognosis in lung cancer patients [40-42] and older patients have a worse outcome compared with younger patients. However, in younger patients with the same TNM stage, tumors 


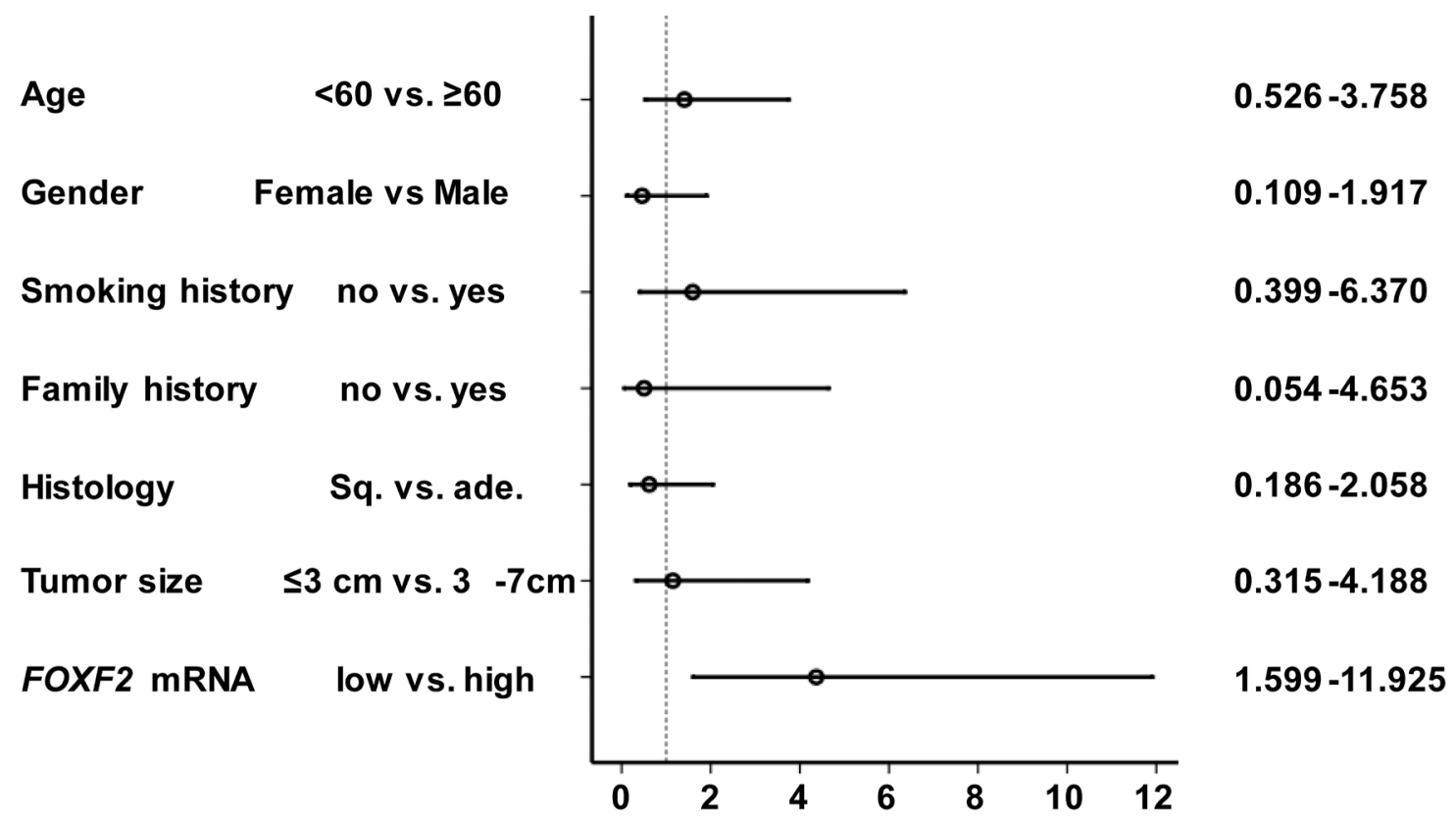

Figure 3: Predictive value of FOXF2 mRNA level in primary cancer tissues for prognosis of patients with stage I NSCLC. Multivariate analysis by cox proportional hazards regression model showed $F O X F 2$ mRNA level was an independent prediction factor for survival of patients with stage I NSCLC.
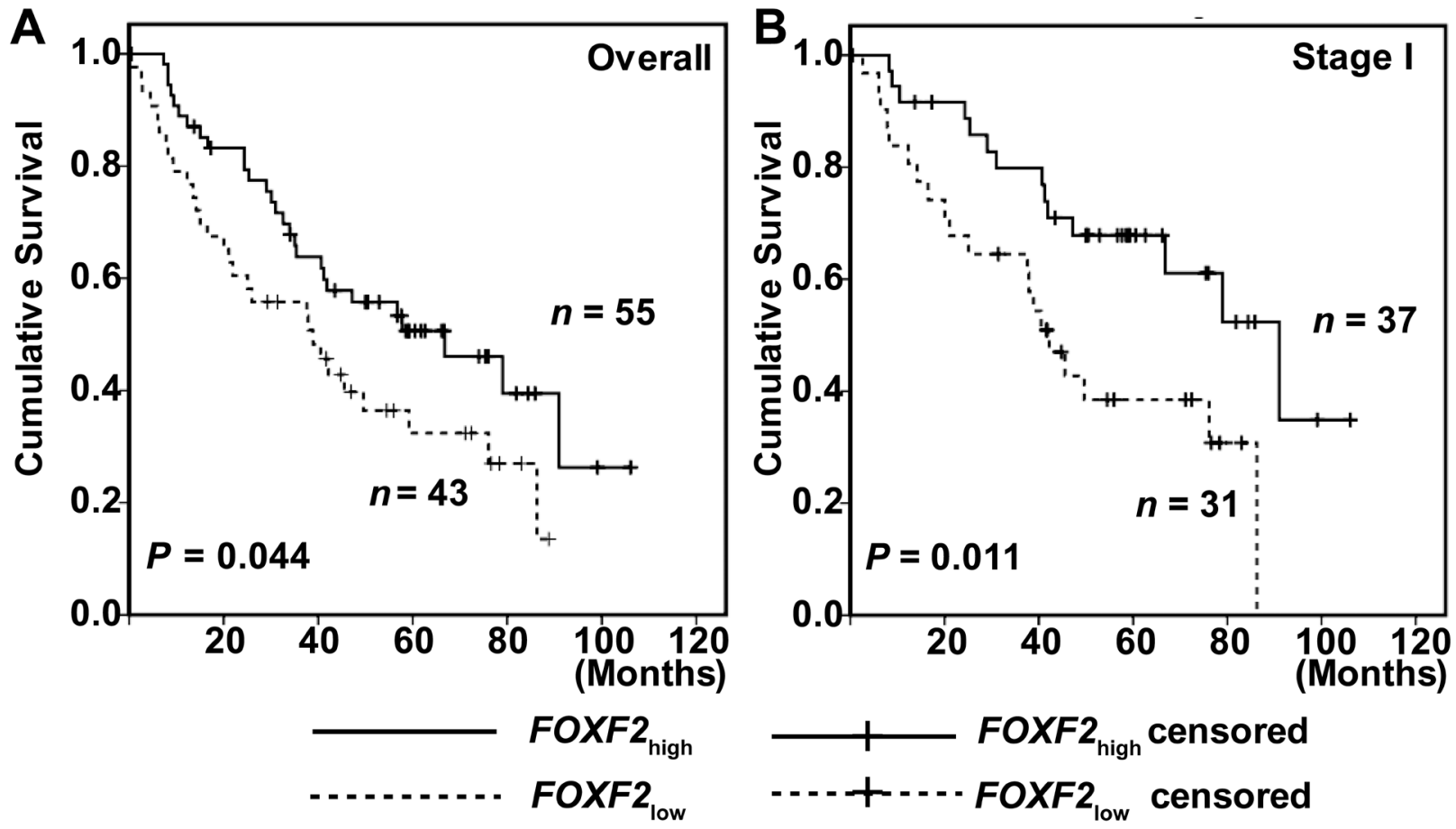

Figure 4: Kaplan-Meier survival curves of patients with different FOXF2 $m R N A$ expression of the independent validation. A. Cumulative DFS in overall independent validation population. B. Cumulative DFS in stage I group of the validation. 
may have different metastatic potential or even form a different metastatic phenotype and lead to a different prognosis. Our investigation revealed that in age $<60$ group, patients with decreased FOXF2 mRNA levels had a lower survival rate than patients with the high $F O X F 2$ mRNA level. FOXF2 mRNA levels might be a potential molecular predictor of prognosis in young patients with NSCLC.

In conclusion, our results demonstrate the prognostic value of $F O X F 2$ mRNA expression in patients with NSCLC. FOXF2 mRNA expression negatively correlates with the size of NSCLC, and patients with high-expressing FOXF2 mRNA have significantly better survival than patients with low-expressing $F O X F 2$. FOXF2 may inhibit growth and metastasis of cancer cells by regulating ECM remodeling and EMT process or other mechanisms. Decreased FOXF2 is a promising candidate for predicting poor prognosis in Stage I NSCLC.

\section{MATERIALS AND METHODS}

\section{Clinical samples}

All 92 lung tissues, including 84 lung cancer and 8 paired normal lung tissues, were collected from lung cancer patients (age range: 40-79; mean age: 62) without preoperative chemotherapy. Patients underwent complete resection of cancer followed by radiotherapy (6 cases), paclitaxel plus cisplatin chemotherapy (43 cases), combined radiation and chemotherapy (13 cases), or supportive care only from June 1995 to January 2005 at Tianjin Cancer Hospital, China. Of these cases, primary cancers and paired normal lung tissues were collected in 8 cases, and only primary cancer samples were obtained in the other 76 cases. Tissue samples were diagnosed as NSCLC using hematoxylin and eosin (H\&E) staining, and only samples with $75 \%$ or more tumor cells in primary tumors were selected for quantitative real-time RT-PCR. Clinical staging of cancer was determined according to American Joint Commission for Cancer (AJCC)/International Union Against Cancer (UICC) TNM staging system and 42, 22,13 , and 7 patients present with stage I, II, III, and IV, respectively. The use of these tissues was approved by the Institutional Reviewing Board and the Research Committee, and written consent was obtained from all participants. Disease-free survival (DFS) time was defined as the time from primary surgery to any relapse (local-regional, contra-lateral and/or distant), death or terminal time of follow-up without any relapse events. Another dataset including 17 normal lung tissues and 98 lung cancer tissues from patients with complete followup data according to the study of Bhattacharjee [19] acts as an independent validation. A large cohort including 2,437 samples of ten independent datasets was used by the online survival analysis software [20].

\section{RNA extraction and CDNA preparation}

Tissue specimens from cancer were snap-frozen in liquid nitrogen within 30 minutes after dissection and then stored at $-80^{\circ} \mathrm{C}$. RNA was extracted with TRIZOL reagent (Life technologies, Gaithersburg, MD, USA) according to the manufacturer's instructions. Five $\mu \mathrm{g}$ of total RNA were used to perform RT for the first-strand cDNA synthesis. In brief, RNA was denatured for 5 minutes at $65^{\circ} \mathrm{C}$ and snapcooled on ice in the presence of $0.5 \mu \mathrm{g}$ Oligo (dT) and $10 \mathrm{mmol} \mathrm{dNTP} \mathrm{mix,} \mathrm{followed} \mathrm{by} \mathrm{incubation} \mathrm{at} 4{ }^{\circ} \mathrm{C}$ for 50 minutes with First-Strand Buffer, $0.2 \mu \mathrm{mol}$ DTT, $40 \mathrm{U}$ RNaseOUT ribonuclease inhibitor and 200 U SuperScript II in total volume $20 \mu \mathrm{L}$ reaction system. Reactions were stopped by incubation at $70^{\circ} \mathrm{C}$ for 15 minutes.

\section{Real-time PCR}

Real-time PCR analysis was performed using the Platinum ${ }^{\circledR}$ Quantitative PCR SuperMix-UDG (Life Technologies) according to the manufacturer's instructions. Primers and Taqman probes of FOXF2 and the housekeeping gene, glyceraldehyde-3-phosphate dehydrogenase (GAPDH), were used as previously described [12]. Assays were performed with the ABI 7500 TaqMan system (Applied Biosystems, Foster City, CA, USA). PCR was carried out after incubation at $50^{\circ} \mathrm{C}$ for 2 minutes and pre-denaturing at $95^{\circ} \mathrm{C}$ for 3 minutes followed by 40 cycles at $95^{\circ} \mathrm{C}$ for $30 \mathrm{~s}$ and $58^{\circ} \mathrm{C}$ for 1 minute. Quantitation of the expression of the target gene in samples was accomplished by measuring the fractional cycle number at which the amount of expression reaches a fixed threshold (CT). The relative quantitation was given by the CT values, determined by triplicate reactions for test and reference samples for the target gene and for GAPDH. Triplicate CT values were averaged and the GAPDH CT was subtracted to obtain $\triangle \mathrm{CT}$. The relative expression level of the target gene was determined to be $2^{-\Delta \mathrm{CT}}$.

\section{Statistical analysis}

The Receiver Operating Characteristic (ROC) curve was used to identify the optimized cut-off value of $F O X F 2$ mRNA level which separated the participants into two groups: the $F O X F 2_{\text {high }}$ group and $F O X F 2_{\text {low }}$ group, respectively. A paired rank-sum test was used to analyze the mRNA expression differences between primary lung cancers and paired normal lung tissue. Wilcoxon ranksum tests or Kruskal-Wallis H tests were used to compare mRNA expression differences between/among different clinicopathologic groups. Survival analysis was carried out according to Kaplan-Meier analysis and Log-rank test. Univariate and multivariate survival analyses were performed by a Cox proportional hazards regression model. All calculations were performed with SPSS for Windows statistical software package (SPSS Inc, Chicago, IL, USA). $P$-values of less than 0.05 were considered statistically significant. 


\section{ACKNOWLEDGMENTS}

We thank Yian Wang (Department of Surgery and the Siteman Cancer Center, Washington University School of Medicine) for the constructive comments and critical review of the manuscript.

We thank Professor Zheng Li (Tianjin Medicine University) for the support of lung cancer samples.

\section{CONFLICTS OF INTEREST}

The Authors do not have any conflicts of interest.

\section{REFERENCES}

1. Jemal A, Bray F, Center MM, Ferlay J, Ward E, Forman D. Global cancer statistics. CA Cancer J Clin. 2011; 61:69-90.

2. Torre LA, Bray F, Siegel RL, Ferlay J, Lortet-Tieulent J, Jemal A. Global cancer statistics, 2012. CA Cancer J Clin. 2015; 65:87-108.

3. Araujo A, Ribeiro R, Azevedo I, Coelho A, Soares M, Sousa B, Pinto D, Lopes C, Medeiros R, Scagliotti GV. Genetic polymorphisms of the epidermal growth factor and related receptor in non-small cell lung cancer--a review of the literature. The oncologist. 2007; 12:201-210.

4. Coffer PJ, Burgering BM. Forkhead-box transcription factors and their role in the immune system. Nature reviews. 2004; 4:889-899.

5. Katoh M. Human FOX gene family (Review). Int J Oncol. 2004; 25:1495-1500.

6. Pierrou S, Hellqvist M, Samuelsson L, Enerback S, Carlsson P. Cloning and characterization of seven human forkhead proteins: binding site specificity and DNA bending. The EMBO journal. 1994; 13:5002-5012.

7. Blixt A, Mahlapuu M, Bjursell C, Darnfors C, Johannesson T, Enerback S, Carlsson P. The two-exon gene of the human forkhead transcription factor FREAC-2 (FKHL6) is located at 6p25.3. Genomics. 1998; 53:387-390.

8. Hellqvist M, Mahlapuu M, Samuelsson L, Enerback S, Carlsson P. Differential activation of lung-specific genes by two forkhead proteins, FREAC-1 and FREAC-2. J Biol Chem. 1996; 271:4482-4490.

9. Aitola M, Carlsson P, Mahlapuu M, Enerback S, PeltoHuikko M. Forkhead transcription factor FoxF2 is expressed in mesodermal tissues involved in epitheliomesenchymal interactions. Dev Dyn. 2000; 218:136-149.

10. Wang T, Tamakoshi T, Uezato T, Shu F, Kanzaki-Kato N, Fu Y, Koseki H, Yoshida N, Sugiyama T, Miura N. Forkhead transcription factor Foxf2 (LUN)-deficient mice exhibit abnormal development of secondary palate. Developmental biology. 2003; 259:83-94.

11. Ormestad M, Astorga J, Landgren H, Wang T, Johansson BR, Miura N, Carlsson P. Foxf1 and Foxf2 control murine gut development by limiting mesenchymal Wnt signaling and promoting extracellular matrix production. Development (Cambridge, England). 2006; 133:833-843.

12. Kong PZ, Yang F, Li L, Li XQ, Feng YM. Decreased FOXF2 mRNA expression indicates early-onset metastasis and poor prognosis for breast cancer patients with histological grade II tumor. PLoS One. 2013; 8:e61591.

13. Wang QS, Kong PZ, Li XQ, Yang F, Feng YM. FOXF2 deficiency promotes epithelial-mesenchymal transition and metastasis of basal-like breast cancer. Breast Cancer Res. 2015; 17:30.

14. Cai J, Tian AX, Wang QS, Kong PZ, Du X, Li XQ, Feng YM. FOXF2 suppresses the FOXC2-mediated epithelialmesenchymal transition and multidrug resistance of basallike breast cancer. Cancer letters. 2015; 367:129-37.

15. van der Heul-Nieuwenhuijsen L, Dits N, Van Ijcken W, de Lange D, Jenster G. The FOXF2 pathway in the human prostate stroma. The Prostate. 2009; 69:1538-1547.

16. van der Heul-Nieuwenhuijsen L, Dits NF, Jenster G. Gene expression of forkhead transcription factors in the normal and diseased human prostate. BJU international. 2009; 103:1574-1580.

17. Hirata H, Ueno K, Shahryari V, Deng G, Tanaka Y, Tabatabai ZL, Hinoda Y, Dahiya R. MicroRNA-182-5p promotes cell invasion and proliferation by down regulating FOXF2, RECK and MTSS1 genes in human prostate cancer. PLoS One. 2013; 8:e55502.

18. Shi W, Gerster K, Alajez NM, Tsang J, Waldron L, Pintilie M, Hui AB, Sykes J, P'ng C, Miller N, McCready D, Fyles A, Liu FF. MicroRNA-301 mediates proliferation and invasion in human breast cancer. Cancer research. 71:2926-2937.

19. Bhattacharjee A, Richards WG, Staunton J, Li C, Monti S, Vasa P, Ladd C, Beheshti J, Bueno R, Gillette M, Loda M, Weber G, Mark EJ, Lander ES, Wong W, Johnson BE, et al. Classification of human lung carcinomas by mRNA expression profiling reveals distinct adenocarcinoma subclasses. Proc Natl Acad Sci U S A. 2001; 98:13790-13795.

20. Gyorffy B, Surowiak P, Budczies J, Lanczky A. Online survival analysis software to assess the prognostic value of biomarkers using transcriptomic data in non-small-cell lung cancer. PLoS One. 2013; 8:e82241.

21. Badve S, Turbin D, Thorat MA, Morimiya A, Nielsen TO, Perou CM, Dunn S, Huntsman DG, Nakshatri H. FOXA1 expression in breast cancer--correlation with luminal subtype A and survival. Clin Cancer Res. 2007; 13:4415-4421.

22. Banham AH, Beasley N, Campo E, Fernandez PL, Fidler C, Gatter K, Jones M, Mason DY, Prime JE, Trougouboff P, Wood K, Cordell JL. The FOXP1 winged helix transcription factor is a novel candidate tumor suppressor gene on chromosome 3p. Cancer research. 2001; 61:8820-8829. 
23. Guttilla IK, White BA. Coordinate regulation of FOXO1 by miR-27a, miR-96, and miR-182 in breast cancer cells. J Biol Chem. 2009; 284:23204-23216.

24. Han CY, Cho KB, Choi HS, Han HK, Kang KW. Role of FoxO1 activation in MDR1 expression in adriamycinresistant breast cancer cells. Carcinogenesis. 2008; 29:1837-1844.

25. Huang H, Muddiman DC, Tindall DJ. Androgens negatively regulate forkhead transcription factor FKHR (FOXO1) through a proteolytic mechanism in prostate cancer cells. J Biol Chem. 2004; 279:13866-13877.

26. Lo PK, Lee JS, Liang X, Han L, Mori T, Fackler MJ, Sadik H, Argani P, Pandita TK, Sukumar S. Epigenetic inactivation of the potential tumor suppressor gene FOXF1 in breast cancer. Cancer research. 70:6047-6058.

27. Maekawa T, Maniwa Y, Doi T, Nishio W, Yoshimura M, Ohbayashi C, Hayashi Y, Okita Y. Expression and localization of FOXO1 in non-small cell lung cancer. Oncology reports. 2009; 22:57-64.

28. Mani SA, Yang J, Brooks M, Schwaninger G, Zhou A, Miura N, Kutok JL, Hartwell K, Richardson AL, Weinberg RA. Mesenchyme Forkhead 1 (FOXC2) plays a key role in metastasis and is associated with aggressive basallike breast cancers. Proc Natl Acad Sci U S A. 2007; 104:10069-10074.

29. Thorat MA, Marchio C, Morimiya A, Savage K, Nakshatri $\mathrm{H}$, Reis-Filho JS, Badve S. Forkhead box A1 expression in breast cancer is associated with luminal subtype and good prognosis. Journal of clinical pathology. 2008; 61:327-332.

30. Wolf I, Bose S, Williamson EA, Miller CW, Karlan BY, Koeffler HP. FOXA1: Growth inhibitor and a favorable prognostic factor in human breast cancer. International journal of cancer. 2007; 120:1013-1022.

31. Zhang H, Fang J, Yao D, Wu Y, Ip C, Dong Y. Activation of FOXO1 is critical for the anticancer effect of methylseleninic acid in prostate cancer cells. The Prostate. 2010; 70:1265-1273.

32. Zhang H, Pan Y, Zheng L, Choe C, Lindgren B, Jensen ED, Westendorf JJ, Cheng L, Huang H. FOXO1 inhibits Runx2 transcriptional activity and prostate cancer cell migration and invasion. Cancer research. 2011; 71:3257-3267.
33. Lee YH, Albig AR, Regner M, Schiemann BJ, Schiemann WP. Fibulin-5 initiates epithelial-mesenchymal transition (EMT) and enhances EMT induced by TGF-beta in mammary epithelial cells via a MMP-dependent mechanism. Carcinogenesis. 2008; 29:2243-2251.

34. Zavadil J, Bottinger EP. TGF-beta and epithelial-tomesenchymal transitions. Oncogene. 2005; 24:5764-5774.

35. Kundu ST, Byers LA, Peng DH, Roybal JD, Diao L, Wang J, Tong P, Creighton CJ, Gibbons DL. The miR-200 family and the miR-183 96 182 cluster target Foxf2 to inhibit invasion and metastasis in lung cancers. Oncogene. 2015: doi:10.1038/onc.2015.1071.

36. Jain MV, Shareef A, Likus W, Cieslar-Pobuda A, Ghavami $\mathrm{S}$, Los MJ. Inhibition of miR301 enhances Akt-mediated cell proliferation by accumulation of PTEN in nucleus and its effects on cell-cycle regulatory proteins. Oncotarget. 2016; 7:20953-20965. doi: 10.18632/oncotarget.7996.

37. Nyberg F, Pershagen G. Passive smoking and lung cancer. Accumulated evidence on lung cancer and environmental tobacco smoke. BMJ. 1998; 317:347-348; author reply 348.

38. Hackshaw AK, Law MR, Wald NJ. The accumulated evidence on lung cancer and environmental tobacco smoke. BMJ. 1997; 315:980-988.

39. Tharappel JC, Cholewa J, Espandiari P, Spear BT, Gairola $\mathrm{CG}$, Glauert HP. Effects of cigarette smoke on the activation of oxidative stress-related transcription factors in female A/J mouse lung. Journal of toxicology and environmental health. 2010; 73:1288-1297.

40. Asmis TR, Ding K, Seymour L, Shepherd FA, Leighl NB, Winton TL, Whitehead M, Spaans JN, Graham BC, Goss GD. Age and comorbidity as independent prognostic factors in the treatment of non small-cell lung cancer: a review of National Cancer Institute of Canada Clinical Trials Group trials. J Clin Oncol. 2008; 26:54-59.

41. Serrano-Olvera A, Gerson R. Age associated survival rate in non small cell lung cancer. Gaceta medica de Mexico. 2009; 145:27-35.

42. Sigel K, Bonomi M, Packer S, Wisnivesky J. Effect of age on survival of clinical stage I non-small-cell lung cancer. Annals of surgical oncology. 2009; 16:1912-1917. 